\title{
Imigração estrangeira, economia e mercado de trabalho na Amazônia brasileira entre o final do século XIX e início do século XX
}

\section{Foreign immigration, economy and labor market in the Brazilian Amazon between the end of the nineteenth century and the beginning of the twentieth century}

\section{Pedro Marcelo Staevie}

Universidade Federal da Integração Latino-Americana (Unila)

\section{Resumo}

O presente artigo busca demonstrar a importância da imigração estrangeira na formação social e econômica da Amazônia brasileira, sobretudo no tocante à sua relevância na conformação de um mercado de trabalho regional. Seja no lado da oferta, seja pelo lado da demanda, os imigrantes estrangeiros tiveram um papel fundamental neste mercado durante as últimas décadas do século XIX e as primeiras décadas do século XX.

Palavras-chave: Amazônia; Imigração; Estrangeiros; Mercado de trabalho.

\section{Abstract}

The present article seeks to demonstrate the importance of foreign immigration in the social and economic formation of the Brazilian Amazon, especially in relation to its relevance in the formation of a regional labor market. Whether on the supply side or on the demand side, foreign immigrants played a key role in this market during the last decades of the nineteenth century and the first decades of the twentieth century.

Keywords: Amazon; Immigration; Foreigners; Labor market. 


\section{Dossiê \\ História Econômica
Demografia Histórica}

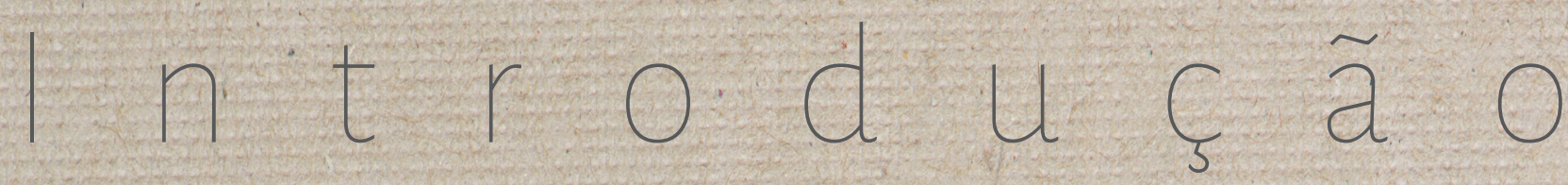

onforme Emmi (2009), um retrato da imigração internacional histórica na Amazônia pode ser encontrado nos dados sobre o movimento imigratório no porto de Belém no início do século XX. Estes dados, compilados por Emmi (2013), aparecem no Anuário Estatístico do Brasil. De acordo com esta fonte, entre 1908 e 1910 entraram pelo porto de Belém aproximadamente 13,5 mil estrangeiros, das mais diversas nacionalidades. Destacam-se os portugueses $(48,67 \%)$, os espanhóis $(15,98 \%)$, os ingleses $(7,18 \%)$, os turcos-árabes $(4,69 \%)$ e os italianos (4,15\%). Já Daou (2000) afirma que, pelo porto de Belém, somente em 1907 mais de 36 mil pessoas entraram no estado, das quais cerca de 11.600 permaneceram na capital, absorvidas pelas atividades comerciais e industriais. Boa parte destas pessoas era oriunda de outros países. Muito provavelmente esse grande afluxo de estrangeiros para a Amazônia está atrelado ao crescimento econômico da região, calcado na economia da borracha. Nesse período, a Amazônia vive o boom da atividade gomífera e esta leva a desdobramentos econômicos e sociais importantes, tais como a expansão comercial, fabril e de serviços, além de um processo de intensa expansão urbana das principais cidades da região.

Já em 1842, a borracha figurava como o terceiro produto no total das exportações brasileiras, chegando ao topo da lista nos anos de 1847 e 1860, o que levou a uma exaltação sobre o ouro branco da Amazônia, e contribuiu para a expansão das imigrações em direção à região (estrangeiros e brasileiros). Entretanto, a riqueza da borracha concentrava-se nas mãos de poucos, como os seringalistas (donos dos seringais). Estes, segundo Santos (2004, p. 35-36), "se juntavam aos estrangeiros ingleses, franceses, alemães, portugueses e outros a quem geralmente confiavam a administração dos seus negócios".

A título de exemplo da riqueza gerada em Manaus durante o período do ciclo da borracha, a primeira casa bancária do estado do Amazonas fundada naquela época foi uma filial da London Bank for South America, quando ainda não existia nenhuma agência bancária de qualquer banco nacional na cidade. Nessa época, a empresa Booth Line, com seus transatlânticos, fazia linhas regulares entre o porto de Manaus e o de Liverpool. Segundo Martins e Sochaczewski 
(2014), Manaus, inclusive, torna-se lugar de destino para turistas estrangeiros. Conforme as autoras, em 1914é lançado o livro Brazil and Brazilians, do inglês George James Bruce, no qual este autor, ao fazer referências às cidades brasileiras que deveriam ser visitadas por turistas estrangeiros, cita a capital amazonense.

Já Belém, ao final de 1894 era cortada por amplas avenidas e grandes estradas direcionadas aos novos bairros da cidade. Praças ajardinadas, edifícios da administração pública, novas escolas e hospitais constituíam a paisagem urbana nesta cidade de ampla expansão urbana, proporcionada pelos impostos advindos das exportações e das importações. Completavam o conjunto urbano da capital paraense diversos estabelecimentos industriais, casas bancárias e firmas seguradoras, além de companhias de serviços públicos como telégrafos, telefonia, linha de bonde e estradas de ferro. Na estação das docas de Belém, duas companhias inglesas ofereciam, a cada dez dias, viagens para Lisboa, Liverpool, Antuérpia, Nova lorque, Havre (DAOU, 2000). Entre Belém e Gênova (e também o sentido inverso), a viagem se dava através do vapor Colombo, da empresa Ligure Brasiliana (GONÇALVES, 2012).

O embelezamento das duas capitais (Manaus e Belém) resultava de alterações urbanísticas e arquitetônicas estimuladas por legislações que buscavam modernizar os espaços públicos e dotar as construções de certas características estilísticas, "imprimindo, na fachada dos prédios, elegância estética, graciosidade e uma racionalidade condizente com as necessidades de ventilação e higiene exigidas pelo clima". Para essas transformações, novos materiais de construção chegavam de vários países da Europa, como Itália, França e Portugal, "de onde vinham também muitos dos profissionais que cuidaram de executar as alterações de estilo" (DAOU, 2000 , p. 32). Grande parte deles permaneceu definitivamente naquelas cidades após a finalização das obras encomendadas.

O período da belle époque amazônica (1880-1910), expressá na transformação urbana modernizante de suas principais capitais, surge em decorrência das expectativas das elites paraense e amazonense entrelaçadas aos interesses de europeus e norte-americanos, visando garantir amplo acesso à borracha e a viabilização do escoamento de estoques de bens industriais (DAOU, 2000). Nesse momento, as elites do Pará e do Amazonas são favorecidas pela crescente utilização da borracha na indústria automobilística. Esta elite acaba por ganhar visibilidade nacional e internacional, auxiliando nos processos de financiamento de obras modernizantes nas duas capitais. Alguns novos bairros foram criados para receber a população imigrante estrangeira. Nesse sentido, são esclarecedoras as palavras de Daou (2000, p. 37), escrevendo sobre Manaus: 
Muitos dos que foram para o Amazonas na década final do século XIX e no início do XX [...] passaram a viver nos novos bairros, nos quais as ruas seguiam o traçado geométrico previsto na carta, livre da tirania dos igarapés e de aspecto mais salubre que o antigo centro. Mesmo a construção das casas refletia um estilo de vida distinto, com uma nítida separação entre os locais de moradia e os de trabalho, valorizando-se as residências situadas em amplos terrenos ou chácaras. No estilo das casas e na disposição dos jardins e pomares, expressava-se a diversidade das origens dos que ali passaram a viver: ingleses, americanos, libaneses e, também, exportadores de borracha, médicos brasileiros.

E segue:

A regularidade ou o ponto em comum entre todos esses recém chegados advinha tanto de sua posição de estrangeiros quanto de seu comportamento mais marcadamente individualista, o que se expressava nos modelos familiares e nas trajetórias dos filhos, comparativamente ao que predominava entre as famílias já estabelecidas. Formava-se um conjunto ruidoso e cosmopolita (DAOU, 2000, p. 37).

Ainda no tocante a Manaus, a autora aponta a criação de vários clubes sociais por parte dos estrangeiros: o Bosque Clube dos Ingleses, o Rudder Clube dos alemães e os clubes portugueses. Também em Manaus e Belém são criados clubes libaneses, e em Belém existiu, naquele momento, uma arena de touradas espanholas, onde se encontra hoje a praça Batista Campos, região central da cidade.

Por outro lado, algumas produções científicas abordam este período tendo como centralidade o trabalho na análise histórica da época - é o caso da dissertação de 'mestrado de Maria Luiza Ugarte Pinheiro (1996), A cidade sobre os ombros: trabalho e conflito no porto de Manaus (78991925). Além de outros aspectos, como as condições laborais dos estivadores manauaras, a autora aborda a organização política da categoria, resgatandó seu processo de organização, que contou com a participação de trabalhadores imigrantes estrangeiros, "as greves e suas dinâmicas, as relações entre lideranças e categorias e outros aspectos" (TELES, 2012, p. 24).

Já a dissertação de mestrado de Luciano Everton Costa Teles (2012), A vida operária em Manaus:imprensa e mundos do trabalho (1920), teve como objetivo central compreender o universo do trabalho e, em especial, a organização e luta operária em Manaus, no início da década de 1920, a partir das páginas do jornal Vida Operária, importante jornal que circulou naquele ano na capital amazonense. O, autor procurou, através deste periódico, "identificar as dimensões (tamanho, composição, características) do universo do trabalho e dos trabalhadores ur- 
banos de Manaus, mapeando ainda as demandas e denúncias acerca das condições de vida e trabalho" (TELES, 2012, p. 25). Buscou, aìnda, analisar a atuação do jornal Vida Operária na organização, conscientização e luta dos trabalhadores de Manaus, identificando, por seu intermédio, "os dilemas organizacionais, as disputas internas, as influências de correntes teóricas no interior do movimento político dos trabalhadores amazonenses" (TELES, 2012, p. 25).

\section{Os imigrantes estrangeiros na economia amazônica}

Os imigrantes estrangeiros distribuíam-se em diversas atividades econômicas. Os ingleses se destacaram na construção de portos, produção de energia, telefonia, telegrafia, saneamento básico, no comércio e no setor de concessão de crédito, onde tinham a concorrência dos norte-americanos e dos franceses. Judeus, africanos do norte e espanhóis se voltaram principalmente para as atividades de escritório e contabilidade. Já os portugueses se encontravam em maior número nas atividades comerciais. Segundo Emmi (2009, p. 265), "os estrangeiros de modo geral deram significativa contribuição na organização dos serviços [...], numa região que dava os primeiros passos na esfera do capital mercantil".

Santos (1980), analisando dados de recenseamentos, aponta uma reduzida presença de estrangeiros na Amazônia brasileira entre 1872 e 1900, tendo inclusive notado uma acentuada queda em números absolutos no período. Somente entre 1900 e 1920 é que a imigração estrangeira se tornou mais expressiva em números absolutos e em proporção ao total da população.

Tabela 1 - Número de estrangeiros residentes na Amazônia (1872-1920).

\begin{tabular}{|c|c|c|}
\hline Anos & Número de estrangeiros & \% sobre a população total \\
\hline 1872 & 8.728 & 2,6 \\
\hline 1890 & 7.316 & 1,5 \\
\hline 1900 & 7.709 & 1,7 \\
\hline 1920 & 39.723 & 2,9 \\
\hline
\end{tabular}

Fonte: Santos (1980)

Santos (1980) afirma ainda poder haver um equívoco quanto ao número de estrangeiros em 1920 por erros no recenseamento, mas destaca que, entre 1908 e 1911, entraram no porto de Belém 19,5 mil imigrantes estrangeiros, especialmente das nacionalidades mencionadas na tabela abaixo: 
Tabela 2 - Imigração estrangeira no quadriênio 1908-1911.

\begin{tabular}{|l|c|c|}
\hline Nacionalidade & Imigrantes & $\%$ \\
\hline Portugueses & 9.008 & 46,3 \\
\hline Espanhóis & 2.809 & 14,4 \\
\hline Ingleses & 1.294 & 6,6 \\
\hline Turco-árabes & 974 & 5,0 \\
\hline Franceses ealemães & 907 & 4,7 \\
\hline Italianos & 830 & 4,3 \\
\hline Norte-americanos & 564 & 2,9 \\
\hline Outros & 3.081 & 15,8 \\
\hline Total & 19.467 & 100,0 \\
\hline
\end{tabular}

Fonte: Santos (1980).

Antes mesmo do ciclo da borracha, a região já contava com um importante contingente de imigrantes de outros países distantes. Fugindo das perseguições, discriminações e até mesmo da fome, judeus sefaraditas marroquinos, por exemplo, assim como outros grupos étnicos aportaram na Amazônia a partir da segunda década do século XIX. A maioria destes imigrantes eram procedentes de Tânger, Fez, Rabat, Sale, Tetuan e Marrakesh (SOUZA, 2009).

Segundo o Centro de Memória da Amazônia (CMA, 2011) Belém é considerada a capital brasileira com maior concentração de judeus marroquinos de tradição sefaradim. Em 1808, o príncipe regente $\mathrm{D}$. João VI abriu os portos do Brasil às potências estrangeiras (a chamada abertura dos portos às nações amigas), fato que admitia o ingresso de pessoas de religião não católica no país. Em 181.0, o tratado de comércio e navegação assinado com a Inglaterra, registrava expressamente em seu artigo 12 que estrangeiros residentes nas possessões portuguesas não seriam perseguidos ou molestados (CMA, 2011).

Esse conjunto de leis, apesar de importante, não explica, de todo, o interesse de judeus marroquinos pela região. Nas últimas décadas do século XIX foram lançados em vários países anúncios buscando atingir trabalhadores e investidores para a Amazônia brasileira. No imaginário dos estrangeiros, as representações da Amazônia oscilavam entre um ambiente hostil e inseguro, e o Eldorado, abundante em oportunidades de enriquecimento (CMA, 2011).

Assim como outros grupos de imigrantes, os judeus sefaradim também contavam com outra fonte de informação e estímulo - a rede de parentescos e até mesmo de amizades que se formava em Belém e Manaus. Conforme aponta texto do CMA (2011) muitas cartas foram trocadas entre os que emigraram e os que permaneceram. Nestas correspondências, as notícias de enriquecimento e prosperidade encorajavam jovens judeus a se aventurar pelas cidades da Amazônia, principalmente nos grandes centros de Manaus e Belém. Mas não apenas nas 
capitais. Em Santarém (PA) também se verificou a chegada de judeus sefaradim, muitos deles exercendo atividades comerciais na cidade, importante entreposto entre as duas grandes capitais da borracha. Ainda segundo texto do Centro de Memória da Amazônia, no início do século XX, já estabelecido, esse grupo de imigrantes se preocupou em consolidar a comunidade regional e nacionalmente.

Já os sírio-libaneses chegaram com mais intensidade entre o final do século XIX e início do século XX, no auge da exploração amazônica da borracha. Segundo Knowlton (1961), entre o final do século XIX e o início da Primeira Guerra Mundial; a imigração síria e libanesa no país cresceu, registrando 11.101 entradas apenas em 1913. Segundo o mesmo autor, este movimento intensificou-se na década de 1920, com cerca de 5 mil entradas anuais.

Os principais portos de entrada desses imigrantes eram Rio de Janeiro, Santos e Recife. O porto de Belém era a principal porta de entrada dos sírios e libaneses que se direcionavam para os estados da Amazônia (ZAIDAN, 2001). Ainda que não na mesma magnitude de estados do sul e sudeste, estes imigrantes foram importantes na composição demográfica dos estados amazônicos. Em 1920, somados os três maiores receptores amazônicos destes imigrantes (Pará, Amazonas e Acre), o censo aponta aproximadamente 3 mil indivíduos.

Analisando os Censos Demográficos de 1920 e 1940, Emmi (2013) aponta que Pará, Mato Grosso, Amazonas e Acre encontravam-se entre os 12 estados com maior número de sírios e libaneses residentes em seus territórios. Em 1920, o Pará abrigava 1.460 destes imigrantes, ocupando a sétima posição geral; o Mato Grosso, 1.232; o Amazonas, 811; e o Acre, 627. Zaidan (2001, p. 64), mostra que a propaganda sobre a Amazônia brasileira era intensa nos portos de emigração:

Era bastante divulgado nos portos marítimos, que o Estado do Pará e a Região Amazônica eram prósperos e ricos devido à época do ciclo da borracha. Em,Beirute já informavam que o Pará exportava cacau, castanha, tabaco, borracha, etc., mais que a exportação da Bolívia, Guatemala, Peru, Paraguai e até o México. A propaganda que faziam era a de que o Pará aumentava sua população por ano em 20.000 habitantes.

Entre as profissões destes imigrantes, destaca-se a de comerciante/negociante-cerca de $85 \%$ dos passageiros (EMMI, 2013). Mas outras profissões aparecem nos relatórios: vendedor ambulante, industrial, ourives, alfaiate, caldeireiro, jornaleiro, seringueiro, agricultor, jornalista, clérigo e cozinheiro. Para a autora, cabe destacar a intensa mobilidade destes imigrantes sírio- libaneses (comerciantes), que se deslocavam dentro da própria região ou mesmo para portos do Nordeste e do Sudeste. 
Francisco (2016), analisando dados do Arquivo Nacional sobre pedidos de naturalização de sírios e libaneses no Brasil nas primeiras décadas do século XX, nos dá alguns exemplos desses processos de imigrantes residentes na Amazônia brasileira, em estados como Pará e Acre. Nessa análise, o autor apresenta algumas características dos imigrantes, como demonstramos abaixo.

Nascido em Jounich, no Líbano, em 1879, Alexandre Nain Auad pede naturalização em 1925. É identificado através da tatuagem de uma cruz no dorso da mão esquerda. Dentista, estabelecido em Belém, casou em 1909 com Zaia Auad, filha de Elias Najun e Joana Maron. Foi testemunha do casamento Jamil Salim (FRANCISCO, 2016).

Chegado ao Brasil em 1913, aos 9 anos de idade, Jaber Calil Nadaf, comerciante em Manaus, solicitou a naturalização aos 35. Dono de imóveis na cidade, casado e com depoimento de três pessoas idôneas, teve seu pedido deferido em maio de 1942 pelo interventor federal no Amazonas. Já Domingos Assmar solicitou nacionalização em Rio Branco (AC), em 1939. Consta que chegou no navio alemão Amazônia pelo porto de Belém em 17 de outubro de 1901 (FRANCISCO, 2016).

Muitos dos imigrantes sírio-libaneses foram pioneiros como industriais, caso da Indústria de Pneumáticos do Pará, dos irmãos Bitar, de origem libanesa, fundada em 1897. Outro importante empreendimento era o Curtume Americano, do libanês Jorge Homci. A fábrica possuía 100 operários e exportava seus produtos a outros estados e ao exterior. As empresas criadas por libaneses eram de diferentes setores, como perfumaria, pneus e borracha, tinturas para cabelos, sabão, alimentos, ferragens, velas, papel e celulose, móveis, etc. Destacam-se ainda as empresas de beneficiamento de castanha, inclusive no interior. Atuavam ainda como trabalhadores no comércio e na indústria nascente, apoiados por uma já existente rede social que os ajudou na inserção no mercado de trabalho urbano local. Também muitos atuavam como jornalistas, advogados, economistas, administradores de empresas, engenheiros, dentistas, médicos, professores, escritores e músicos.

Quanto aos italianos, segundo Emmi (2013) a motivação principal para o deslocamento em direção à Amazônia foi a busca pelas riquezas decorrentes da exploração da borracha. De acordo com o texto retirado do site do CMA (2011) um grupo significativo entre os italianos era formado por religiosos que vinham por determinação de suas respectivas congregações, tendo esses imigrantes deixado suas marcas em estabelecimentos de ensino e hospitais. Outro grupo importante era composto por arquitetos, pintores, músicos e demais artistas. 
Embora o número de imigrantes que se dirigiram para a Amazônia seja menos expressivo se comparado com os que foram para o Sul e Sudeste do Brasil, evidências empíricas permitem agrupar os imigrantes italianos em dois grandes segmentos: os que foram para as colônias agrícolas, através de imigração subsidiada, e os que se dirigiram para as cidades de forma espontânea. A imigração dos dois segmentos ocorreu simultaneamente, entretanto, diferenciadas quanto às razões norteadoras do movimento migratório, à composição social, à origem regional e às áreas de destino dentro da Amazônia.

Os imigrantes que se dirigiram para as colônias agrícolas no Pará eram formados por grupos familiares de agricultores que, em 1899, em navios da companhia La Ligure Brasiliana, deixaram a Itália para povoar as colônias agrícolas de Anita Garibaldi e lanetama, localizadas respectivamente às margens da estrada de ferro Belém-Bragança, no atual município de Castanhal, e na colônia modelo de Outeiro, no distrito de Icoaraci, em Belém.

Para a colônia Anita Caribaldi, dirigiram-se imigrantes do Vêneto, Lombardia, Piemonte e Emilia Romagna. Para lanetama, foram italianos do Vêneto, da Campania e da Sicília. Já Para Outeiro, foram colonos do Vêneto. As colônias agrícolas com estrangeiros eram iniciativa do governo da província do Pará, preocupado com a falta de mão de obra para a produção alimentícia, haja vista o grande deslocamento de pessoas das áreas rurais em direção aos seringais para a exploração da borracha (EMMI, 2013).

A procedência regional dos italianos que foram para as cidades amazônicas era bastante diversificada. Algumas famílias tinham origem na Itália setentrional, das regiões do Vêneto, Lombardia, Emilia Romagna, Piemonte e Ligúria, ou da Itália central, região do Lazio e da Toscana, e ainda da Sicília. Entretanto, a maioria dos imigrantes (aproximadamente $90 \%$ ) era oriunda da Itália meridional, principalmente das regiões da Calábria, Basilicata e Campânia, tendo constituído um grupo mais numeroso do que o da colonização dirigida para as colônias agrícolas, assim como com maior continuidade (EMMI, 2013). A origem da maioria dos imigrantes italianos que foram para Amazônia difere do grupo que se dirigiu para o sul do país, oriundos principalmente de regiões do Vêneto e Lombardia.

Os italianos se dirigiram principalmente às cidades, fixando-se em Belém, Manaus e em alguns municípios localizados ao longo do rio Amazonas e de seus principais afluentes, por onde circulava o capital mercantil decorrente da economia gomífera. Demasi (2015), além dos residentes em Manaus, elenca famílias italianas que se fixaram em municípios do interior do Amazonas, como Maués (muitos deles produtores, industriais e comerciantes de guaraná), Parintins, Uaupés, Urucurituba e Itacoatiara. Na capital amazonense, Demasi (2015) mostra 
uma extensa diversidade laboral entre os imigrantes italianos: desde empresários de diversos setores econômicos (dando continuidade aos seus negócios no país de origem), profissionais dos ramos de sapataria, alfaiataria, ourivesaria, funilaria, marmoraria, mercearia, bares, bazares, barbearia, até profissionais liberais como arquitetos, engenheiros, médicos e advogados, e ainda maestros, músicos, pintores, atores e escritores e outros artistas. Assim, percebe-se que os italianos inseriram-se em diferentes setores da economia, proporcionado pelo crescimento urbano que proporcionava condições favoráveis e criava um mercado de atividades de prestação de serviços que acabou atraindo boa parte dos imigrantes que chegavam às cidades (EMMI, 2009). Ainda conforme o Centro de Memória da Amazônia (2011) os imigrantes italianos também tiveram importante participação nos primórdios da indústria paraense, a partir da criação das empresas beneficiadoras de sementes oleaginosas Victoria e Conceição, instituídas na década de 1920".

Vale destacar que muitos dos anúncios dos estabelecimentos comerciais e industriais de propriedade de imigrantes italianos eram redigidos no idioma de origem pátria. $\mathrm{O}$ anúncio abaixo, retirado de Demasi (2015, p. 149), é um bom exemplo desta prática:

Lattoneria italiana di Francesco Celani. Avenida Eduardo Ribeiro, 57-Manaos.

Questa Ditta, stabilita sin dal 1910, é tra quelle che godono di maggior considerazione in Manaos e di maggior favore fra ll pubblico cittadino. Ottimamente montata, essa si occupa di qualsiasi lavoro attiente al su ramo. II suo proprietario, signor Francesco Celani, venne in Brasile nel 1900, dal ridente paese di Castelluccio Inferiore, ov'era nato nel 7890. Durante questi 32 anni il signor Celani fu piú volte a visitare la Patria?.

Este anúncio é, como dito, bom exemplo da prática dos comerciantes italianos fazerem a propaganda de seus estabelecimentos na língua materna, o que evidencia seu foco na formação da clientela junto à comunidade de imigrantes italianos, então composta por cerca de 2 mil pessoas apenas em Manaus, e igual número em Belém (CENNI, 2003).

Em suma, o número de imigrantes italianos que se dirigiram para a Amazônia não é desprezível: eles foram importantes no mercado de trabalho urbano nas principais cidades da região, em particular em Belém e Manaus. Tanto no lado da oferta, como da demanda, os italianos tiveram participação importante na formação de um mercado de trabalho na Amazônia brasileira no final do século XIX e nas primeiras décadas do século XX.

1 Lattoneria italiana de Francesco Celani. Avenida Eduardo Ribeiro, 57 - Manaos. (Tradução livro do autor).

Esta empresa, criada desde 1910, está entre as que gozam de maior prestígio em Manaos e maior favor entre os cidadãos. Otimamente montada, cuida de qualquer trabalho que seja relevante para o ramo. Seu dono, o Sr. Francesco Celani, chegou ao Brasil em 1900, da encantadora vila de Castelluccio Inferiore, onde nasceu em 1890. Durante esses 32 anos, o Sr. Celani visitava repetidamente o país. 
No tocante aos movimentos operários, Emmi (2009) aponta que estes imigrantes, muitos deles com inspiração anarquista, cumpriram um importante papel, embora este tipo de estudo mereça maior destaque, ainda carente de maiores aprofundamentos. Outros imigrantes importantes na formação do mercado de trabalho urbano amazônico no período considerado foram os portugueses e os espanhóis, analisados a seguir.

\section{Imigrantes ibéricos na formação do mercado de trabalho na Amazônia}

\section{Os espanhóis no Pará}

O censo de 1872 apontava a existência de 158 espanhóis vivendo no Pará, atrás apenas dos portugueses (4.463) e franceses (210). Em número menor que no Pará, encontravam-se ainda, no Amazonas, 35 imigrantes espanhóis, correspondendo à terceira maior colônia de imigrantes estrangeiros no estado, suplantada pelos portugueses (689) e ingleses (56).

Conforme aponta Emmi (2013), em 1894 o vice-cônsul da Espanha em Belém apresentou informações que mostravam a existência de 600 espanhóis residindo na cidade, em sua maioria oriunda da Calícia. A partir de então, houve um aumento significativo na entrada de espanhóis no Pará, principalmente para as colônias agrícolas criadas na região bragantina. Estas colônias eram tentativas do governo do Pará em resolver o problema da falta de mão de obra para a produção de alimentos, haja vista que uma importante parcela de pequenos produtores agrícolas se deslocou para os seringais em busca do tão almejado ouro branco.

Em 1896, uma lei paraense autorizou o então governador Lauro Sodré a promover a entrada de 100 mil imigrantes do exterior até o ano de 1906. Para Santos (1980), a concorrência do sul acabou prejudicando o alcance desta meta. Entre 1896 e 1900, apenas 13.299 estrangeiros (dos 50 mil esperados) aportaram no Pará, quase todos portugueses e espanhóis. Desses, somente 9.616 teriam idades entre 12 e 45 anos, considerados mais aptos para exercer trabalho. E ainda, 5.407 pareciam não ter nenhum tipo de qualificação, pois em seus registros constava sem profissão declarada.(SANTOS, 1980, p. 92).

O seguinte trecho do relatório do governador Lauro Sodré, de 01 de fevereiro de 1897, demonstra a política de atração de imigrantes estrangeiros para as colônias agrícolas paraenses por parte do governo do estado: 
Aos 15 de agosto e aos 15 de novembro de 1895 firmaram-se, na repartição de obras publicas, os primeiros contractos, com cidadãos Fancisco Cepeda, Emilio A.C. Martins e William Brice, para a introdução de 35.000 immigrantes de várias nacionalidades europeias e das Antilhas, e a 21 de Agosto de 1895 foi contractado com o cidadão Julio Benavides representante da companhia oriental de immigração e commercio, a introducçao de 3.000 japonezes (SMITHJÚNIOR \& GARVÃO, 2015, p. 175).

O governo do Pará estabeleceu como agentes da introdução de imigrantes no estado Francisco Cepeda, Heliodoro Jaramillo e Emílio Martins, determinando que os contratantes ficassem obrigados a custear a propaganda nos países de potenciais imigrantes. Nessa linha, em 1895 foi editado, em Barcelona, um livro intitulado El Pará, visando atrair espanhóis para o estado. Em 1896, foram introduzidos 3.168 imigrantes espanhóis, dos quais 1.777 partiram para os núcleos agrícolas e 1.368 ficaram na capital. Grande parte dos espanhóis seguiu para os núcleos coloniais de Monte Alegre e Bragança, e outros se empregaram em estabelecimentos industriais da capital e do interior, ou como criados em casas de famílias (CMA, 2011).

Os principais núcleos coloniais de imigração espanhola foram os de Benjamim Constant, Ferreira Pena, Jambu-Açu, Marapanim, Santa Rosa e Monte Alegre. Na região do Salgado, no nordeste paraense, muitos imigrantes espanhóis saíram de seus núcleos de destino e foram para outras terras, se instalando em áreas próximas aos núcleos, dando origem a vilarejos como Simão e Mocajuba, às margens do rio Caeté, formados a partir de uma reemigração de algumas famílias de espanhóis e nordestinos no final do século XIX (CMA, 2011).

Muitas famílias espanholas que chegaram ao núcleo de Benjamin Constant não resistiram às adversidades encontradas na região e, decepcionadas com as falsas promessas do governo paraense, decidiram retornar à Espanha. Outros migraram para as cidades mais desenvolvidas e mais próximas do núcleo de Benjamim Constant, como Bragança e outros tantos migraram para Belém. Os imigrantes exerceram suas atividades não apenas na agricultura, mas também no comércio de manufaturas, nos transportes de alimentos, e nas usinas de beneficiamento. No tocante aos problemas enfrentados pelos colonos e o consequente esvaziamento das colônias, Martínez (2005, p. 5) afirma que

Otros testimonios reflejaban lo difícil que resultaba la vida cotidiana en los primeros meses, sobre todo si no se podía contar con los suministros alimenticios que proporcionaba la administración. En realidad una de las críticas que podemos hacer es que las autoridades no disponían de recursos suficientes para llevar adelante la empresa, mientras que los encargados de la recluta sólo perseguían reunir el número suficiente de candidatos, sin tener en cuenta su capacitación; 
por último; los colonos fueron incapaces de aunar sus esfuerzos para superar las primeras dificultades ${ }^{2}$.

Alguns dados mostram números referentes à entrada de espanhóis no Pará. Segundo Sarges (2010), o relatório do secretário Manuel Baena, de 1897, apresenta ao governo do Pará a informação de que, no ano anterior, havia sido registrada a entrada de 3.145 imigrantes espanhóis em terras paraenses, sendo que 1.777 se direcionaram aos principais núcleos do estado, como Jambu-Açu, Monte Alegre e Benjamin Constant. O restante (1.368) acabou se instalando na capital paraense (SMITH JÚNIOR \& GARVÃO, 2015).

Em 1900, o censo das colônias agrícolas apontou a existência de 3.283 imigrantes espanhóis residindo em 10 colônias agrícolas do estado do Pará. Entretanto, apenas dois anos depois, em 1902, é desativado o programa de colônias agrícolas com imigrantes estrangeiros no Pará, levando a um deslocamento destes para as principais cidades da região, em particular para Belém. Lá, juntam-se às levas de imigrantes que haviam chegado de forma espontânea na cidade.

Mesmo com o fim do programa de colônias agrícolas com imigrantes estrangeiros em 1902, 0 movimento imigratório para o Pará continuou, de onde se infere que os imigrantes estrangeiros passaram a se dirigir às cidades. O anuário estatístico do Brasil mostra que cerca de 13.500 estrangeiros de diversas nacionalidades entraram pelo porto de Belém entre 1910 e 1912, a maioria oriunda de Portugal $(48,67 \%)$ e da Espanha (15,98\%). No período, entraram pelo porto de Belém 2.139 espanhóis, perfazendo uma média anual de 713 entradas.

Em publicação de 1916, o inspetor espanhol de emigração, Leopoldo D’Ouzeville (1916), relatou que a maioria dos imigrantes espanhóis era originária da Galícia, particularmente de Orense. As principais atividades econômicas exercidas pelos homens eram a de sapateiro e afiador de ferramentas, enquanto as mulheres costumavam ser lavadeiras, passadeiras ou empregadas domésticas.

As mulheres, na sua quase totalidade, declararam como ocupação os serviços domésticos ou prendas do lar, sendo contabilizadas apenas três exceções: duas mulheres que se declararam modistas, e uma professora, o que, segundo Emmi (2013, p. 88) seria "compatível com o lugar ocupado pela mulher na sociedade da época".

2 Outros testemunhos refletiram o quão difícil foi a vida diária nos primeiros meses, especialmente quando não se podia contar com os suprimentos alimentares distribuídos pela administração. Na verdade, uma das críticas que podemos fazer é que as autoridades não dispunham de recursos suficientes para realizar a empresa, enquanto os responsáveis pelo recrutamento estavam apenas tentando reunir um número, suficiente de imigrantes, sem levar em consideração a capacitação profissional dos mesmos; por fim, os colonos não conseguiram juntar seus esforços para superar as primeiras dificuldades. (Tradução livro do autor) 
No tocante aos homens, Emmi (2013, p. 88), afirma que

As profissões declaradas com mais freqüência foram comerciante, artista, jornaleiro e sapateiro, seguidas de outras profissões de menor freqüência: alfaiate, açougueiro, carpinteiro, cozinheiro, carroceiro, chofer, estivador, jardineiro, mecânico, marítimo, maquinista, vendedor ambulante, entre outras. Entre os nubentes estão relacionados um advogado, um dentista, um professor, um enfermeiro, um guarda-livros, três industriais, que diferem do perfil do nível de instrução comumente associado ao imigrante espanhol.

No que diz respeito às condições de vida e laborais dos espanhóis residentes no Pará, Martínez (2005, p. 8) faz referência a um informe enviado em 1901 pelo vice-cônsul ao Encarregado de Negócios da Espanha no Brasil, nos seguintes termos:

La pobreza en que han quedado reducidos la mayoría de los miembros de esta colonia por la enorme crisis que afectó a todas las clases sociales de esta región, [...] cerca de tres mil españoles quedan todavía en este estado, de los nueve o diez mil venidos en la emigración, que son otros tantos pobres que en estado lastimoso necesitan a todo momento, que este Viceconsulado les oiga, les ayude y les sirva gratuitamente en sus pedidos y reclamaciones ${ }^{3}$

Embora vivendo em condições materiais precárias, trabalhando nos mais diversificados serviços, esses sujeitos não deixaram de preservar seus costumes e tradições, como as touradas que ocorriam todos os domingos no Colyseu Paraense, situado na praça Batista Campos, região central da cidade, reforçando os laços de identidade com a pátria de origem (CMA, 2011).

\section{Espanhóis no Amazonas}

Não existem indicativos de uma política de agenciamento de imigrantes estrangeiros para colônias agrícolas no Amazonas como ocorrera no Pará entre 1896 e 1902, ano de interrupção da referida política. Para o Amazonas, a imigração espanhola foi tipicamente urbana, em particular para Manaus. Segundo Silva (2010), em 1900 havia aproximadamente 3 mil espanhóis residindo na capital amazonense.

Samuel Benchimol (2008, apud EMMI, 2013 p. 89), utilizando dados da Revista da Associação Comercial do Amazonas, informa que entre os recebedores eaviadores da borracha em Manaus, havia cinco firmas em que os proprietários eram de origem espanhola: Suarez, Hermanos \& Cia.; J.C.C. Araña \& Hermanos; M.M. Cobracho e Cia.; R. Suarez \& Cia.; e C.C.M. Asensi e Cià. (EMMI, 2013). Ainda segundo Emmi (2013), após o declínio da borracha, muitos espanhóis que haviam se estabelecido

3 Tradução livre: A pobreza a que foi reduzida a maioria dos membros desta colônia pela enorme crise que afetou todas as classes sociais desta região, [...] quase três mil espanhóis ainda estão neste estado, dos nove ou dez mil vindos na emigração, que são tantos pobres que no estado lamentável em que se encontram precisam a todo o momento, que este vice-consulado os ouça, os ajude e os sirva livremente em seus pedidos e reivindicações. 


\section{História Econômicag Dossiê}

em cidades do interior do Amazonas acabam se transferindo para a capital, localizando os seus estabelecimentos comerciais nas áreas de panificação, livraria, sapataria, funilaria, ourivesaria, ou ocupando-se no setor de serviços. Ao descrever a trajetória de alguns irmãos espanhóis, a autora mostra a diversidade laboral exercida por estes imigrantes em terras manauaras:

Segundo Nóvoa Silva (2010), os irmãos Modesto, Urbano, David e Elias Nóvoa eram originários de Castro de Esquadro, Orense, região da Calícia. Ao chegarem em Manaus, no início do século XX, os dois primeiros, após passarem pelas dificuldades comuns aos imigrantes, trabalharam como enfermeiros no Hospital Colônia de Alienados Eduardo Ribeiro, hoje Hospital Psiquiátrico Eduardo Ribeiro. O imigrante Urbano Nóvoa chegou a ocupar o cargo de diretor desse hospital por várias décadas. Elias Nóvoa começou trabalhando como padeiro, depois trabalhou em olaria na produção de telhas e tijolos. Posteriormente, em 1946, os irmãos David e Elias Nóvoa compraram a cerâmica Marajó, inaugurando o ingresso da família Nóvoa na produção de cerâmica para construções, ramo que teve continuidade através dos descendentes (EMMI, 2013, p. 89).

A tabela 3 mostra o número de imigrantes espanhóis registrados no Vice-Consulado da Espanha em Manaus, por ano de chegada do imigrante, no período entre 1899 e 1910.

Tabela 3 - Imigrantes registrados no Vice-Consulado da Espanha em Manaus por ano de chegada.

\begin{tabular}{|l|c|}
\hline Nome & Ano \\
\hline Francisco Cordon Cuquejo & 1899 \\
\hline Francisco Martinez Fagundes & 1901 \\
\hline Manoel Maria Salgado & 1904 \\
\hline Modesto Nóvoa Alvarez & 1906 \\
\hline Luís Esteves Fernandez & 1907 \\
\hline Ramon Mangana Ribas & 1910 \\
\hline Delmiro Figueredo Lopes & 1910 \\
\hline José Prieto Rodrigues & 1910 \\
\hline
\end{tabular}

Fonte: Elaborado pelo autor a partir de Emmi (2013, p. 90).

Em Manaus havia três associações: a Sociedade Espanhola de Socorros Mútuos; a Sociedade Espanhola Recreativa e de Beneficência e o Centro Espanhol. O vice-cônsul da Espanha na cidade, David Nóvoa Alvarez e Ramon Mangana, ambos de nacionalidade espanhola, fundaram ainda a Sociedade Beneficente Mútua repatriadora, "com o objetivo de custear as despesas dos espanhóis que não tendo recursos, desejassem voltar à Pátria". (EMMI, 2013, p. 93-94).

\section{Os portugueses}

No período do auge da atividade gomífera, diversas firmas comerciais portuguesas se estabeleceram na Amazônia, em particular em Manaus e em Belém, "suprindo de mercadorias à base do sistema de aviamento, ou seja, dando crédito pessoal em troca de produtos extrativos 
destinados à exportação" (ARAGÓN, 2013, p. 226). Mas, neste período, houve ainda uma imigração de portugueses pobres envolvidos em pequenos serviços ou empregados em pequenos comércios.

Em 1920, o Pará figurava em quarto lugar (excluindo o Distrito Federal), e o Amazonas o sexto lugar entre os estados receptores de portugueses, com 14.211 e 7.615 imigrantes respectivamente. Ainda antes, em 1872 (Censo Demográfico), verifica-se a presença de 4.423 portugueses no Pará ( $71,3 \%$ do total de 6.259 estrangeiros no estado), enquanto no Amazonas havia 689 , perfazendo $31,33 \%$ do total de imigrantes estrangeiros no estado.

Segundo Fontes (2009), a imigração portuguesa caracteriza-se como masculina e individual (solteira). Entretanto, registraram-se também, na Amazônia, experiências subsidiadas de imigração rural no período imperial e no início do período republicano: "existem registros de uma imigração subsidiada de portugueses direcionada às colônias agrícolas, embora em número pouco significativo" (EMMI, 2013, p. 39).

Segundo Fontes (2009), a maior parcela de imigrantes portugueses se dirigiu para as cidades, notadamente Belém e Manaus. Entretanto, registrou-se a ocorrência destes imigrantes em cidades como Santarém, Barcelos e Macapá. Quanto à origem dos imigrantes, destacam-se as províncias do Douro, Minho, Beira Alta, Estremadura, Beira Baixa (FONTES, 2009). A maioria dos imigrantes partiu de Lişboa, Leixões e Porto. Para a autora, a atração da mão de obra portuguesa se dava diretamente no país de origem, através, sobretudo, de engajadores, personagens que atuavam "entre o imigrante e as companhias ou entidades ligadas diretamente ao recrutamento de mão-de-obra" (FONTES, 2009, p. 290).

No que tange à profissão, encontravam-se caixeiros, comerciantes, marítimos, carpinteiros, pedreiros, alfaiates, padeiros, trabalhadores avulsos, dentre outras. Muitos portúgueses eram proprietários de estabelecimentos comerciais e industriais, onde empregavam muitos conterrâneos. Percebe-se, assim, a presença dos portugueses nos lados da oferta e da demanda de trabalho na Amazônia, ajudando a conformar um mercado de trabalho urbano na região.

Edilza Fontes (2009, p. 295), analisando a imigração portuguesa para Belém entre 1844 e 1914, afirma que a quantidade de portugueses que sabiam ler e escrever era bem superior ao número de analfabetos, o que indicaria que "os portugueses que vieram para o Pará, provavelmente representavam uma mão de obra urbana". Aponta ainda que a maioria dos imigrantes fazia o movimento imigratório sozinho, "demonstrando sua aptidão com um trabalho urbano sem vínculo com a terra”. (FONTES, 2009, p. 295). Enumera os trabalhadores do comércio, os caixei- 
ros e os marítimos como os mais representativos numericamente nas profissões de prestação de serviço exercidas por portugueses entre 1884 e 1914.

Fontes (2009) destaca também o papel dos portugueses no movimento operário belenense ao final do século XIX e início do século XX, ajudando a formação dos primeiros sindicatos de trabalhadores na capital paraense. Segundo a autora, os estatutos sindicais "parecem reafirmar os ensinamentos revolucionários que defendiam a participação dos anarquistas nos sindicatos e que estes deveriam ser um instrumento para a libertação operária", sendo possível notar "a relação estreita com os ensinamentos anarquistas na forma de organizar os sindicatos e as greves, de prepararema ação direta, como princípio norteador dos estatutos dos sindicatos" (FONTES, 2009, p. 315).

Já Teles (2016) destaca a importância dos imigrantes no movimento operário anarquista na Amazônia. O autor procura demonstrar a construção de uma rede regional anarquista, através do jornal A Lucta Social (1914), editado em Manaus, e dos militantes que estavam por trás do periódico, particularmente o português Tércio Miranda (responsável direto pela folha). Analisa também o português Antônio Costa Carvalho, residente em Belém e proprietário de uma quitanda. Era um militante anarquista, propagador e formador no interior do movimento operário na capital paraense, sendo uma das principais lideranças das greves ocorridas na cidade nos anos de 1913 e 1914. Segundo Teles (2016, p. 13), "a sua quitanda se caracterizava como um espaço de convivência onde os trabalhadores discutiam seus problemas, podendo até mesmo se converterem ao anarquismo".

As análises destes dois últimos autores são importantes no sentido de trazerem luz aos estudos gerais sobre a economia urbana amazônica no período considerado (final do século XIX/início do século XX) e, particularmente, acerca do movimento operário da região, com destaque ao papel dos imigrantes estrangeiros (no caso, portugueses) neste movimento.

\section{Considerações finais}

Ainda que não nas mesmas proporções de outras regiões do país, como o centro-sul, a Amazônia brasileira recebeu uma importante leva de imigrantes estrangeiros que se direcionou para os campos e cidades, ajudando a conformar um mercado de trabalho, sobretudo urbano, na região.

Para o campo, destacam-se os espanhóis, principalmente através da política de criação de colônias agrícolas na zona bragantina paraense; e os japoneses (não abordados neste ensaio), 
para diversas áreas rurais, tanto do Amazonas, como do Pará. Também estes (em pequeno número, é verdade) foram direcionados para os atuais estados de Rondônia e Roraima. Mas também se dirigiram para as áreas rurais portugueses, italianos, franceses, dentre outros.

Já para as cidades, dirigiram-se portugueses, espanhóis, sírio-libaneses, italianos, alemães, ingleses e imigrantes de outras nacionalidades. Nelas, além de proprietários de estabelecimentos comerciais e industriais, exerciam diversas atividades liberais, atuando como médicos, advogados, dentistas, economistas, administradores de empresas, engenheiros, arquitetos etc. Também estavam presentes nas artes, como escritores, músicos, maestros, pintores, atores. Exerciam ainda a profissão de padeiros, pedreiros, montadores de móveis, caixeiros, carpinteiros, alfaiates, marítimos, açougueiros, estivadores etc. Assim, grande parte dos imigrantes era de trabalhadores empregados em estabelecimentos de compatriotas (ou de outros estrangeiros) e também de brasileiros, formando o lado da oferta de trabalho no mercado urbano regional.

Em suma, os imigrantes estrangeiros que aportaram nas principais cidades da Amazônia brasileira nas últimas décadas do século XIX e no início do século XX foram fundamentais para a conformação do mercado de trabalho regional no período considerado. Mesmo sabendo da controvérsia a respeito da formação ou não de um mercado de trabalho urbano fora do eixo Rio-São Paulo neste período 4 , afirmamos que na Amazônia brasileira se constituiu sim este mercado, fortemente amparado na participação (dos lados da oferta e da demanda de trabalho) dos imigrantes estrangeiros que para lá se dirigiram.

Concordamos com Fontes (2009) quando afirma que pensar a formação do mercado de trabalho é terem mente que o mesmo resulta de diversidades múltiplas, inclusive do ponto de vista das nacionalidades dos agentes sociais que ajudam (e ajudaram) na conformação deste mercado. No caso da Amazônia brasileira, como em outras regiões do país, é mister compreender que os estrangeiros foram fundamentais na estruturação do mercado de trabalho urbano, seja no âmbito da oferta, como na demanda por trabalho. Mais uma vez recorremos a Fontes (2009, p. 281), quando afirma a necessidade de "entender a conjuntura da efervescência da sociedade amazônica no período áureo da economia da borracha do ponto de vista da formação de um mercado de trabalho urbano". Ao citar o caso de Belém (que podemos estender a Manaus, por exemplo), a referida autora nos brinda com a seguinte afirmação: "uma cidade onde os bancos, as casas aviadoras e as empresas vinculadas à prestação de serviços urbanos exigiram um mercado de trabalho que se formou dialogando com trabalhadores vindos de diversas partes do mundo" (FONTES, 2009, p. 281).

Por fim, buscamos destacar a importância dos trabalhadores imigrantes estrangeiros nos mo-

4 Sobre essa controvérsia, sugerimos a leitura de Lima e Oliveira [1980?] e Barbosa (2008). 
vimentos operários no início do século XX, nas principais cidades da Amazônia no período em questão. Fontes indicam a participação de portugueses, espanhóis e italianos nestes movimentos, inclusive na divulgação do ideário anarquista, a partir de periódicos que circularam nas capitais amazonense e paraense à época.

\section{Referências}

ARAGÓN, Luis E. Amazônia, conhecer para preservare conservar: cinco temas para um debate. São Paulo: Hucitec, 2013.

BARBOSA, Alexandre de Freitas. A formação do mercado de trabalho no Brasil. São Paulo: Alameda, 2008.

CENNI, Franco. Italianos no Brasil: Andiamo in`America. 3.ed. São Paulo: Edusp, 2003.

CENTRO DE MEMÓRIA DA AMAZÔNIA (CMA). Projeto Imigração. 2011. Disponível em:<http://www.ufpa.br/ cma/imigracao/imigracao.html>. Acesso em: 25 maio 2017.

D'OZUVILLE, Leopoldo. Un viaje a Brasil: información acerca de la situación de los emigrados españoles en los estados de Pará y Amazonas y zonas de trabajo del ferrocarril Madeira-Mamoré. Madrid: Consejo Superior de Emigración, 1916.

DAOU, Ana Maria. A belleépoque amazônica. 2. ed. Rio de Janeiro: Jorge Zahar, 2000.

DEMASI, Luiz Geraldo. Italianosem Manaus. 2. ed. Manaus: Reggo, 2015.

EMMI, Marília Ferreira. Fluxos migratórios internacionais para a Amazônia brasileira do final do século XIX: o caso dos italianos. In: ARACÓN, Luis E. (Org.). Migração Internacional na Pan-Amazônia. Belém: NAEA, 2009. p. 263-279.

Um século de imigrações internacionais na Amazônia brasileira. Bélém: NAEA, 2013.

FONTES, Edilza. O. Imigração e mercado de trabalho na Amazônia do fim do século XIX: o caso dos portugueses em Belém do Pará. In: ARACÓN, Luis E. (Org.). Migração Internacional na Pan-Amazônia. Belém: NAEA, 2009. p. 281-319.

FRANCISCO, Julio Bittencourt. Brasilerando: pedidos de cidadania de imigrantes sírios e libaneses nas primeiras décadas do século XX. Acervo-Revista do Arquivo Nacional, Rio de Janeiro, v. 29, n. 1, p. 189-206, jan./ jun. 2016. Disponível em: $<$ http://revista.arquivonacional.gov.br/index.php/revistaacervo/article/view/628> . Acesso em: 22 fev. 2018.

CONÇALVES, Paulo Cesar. Mercadores de braços: riqueza e acumulação na organização da emigração europeia para o Novo Mundo. São Paulo: Alameda, 2012. 
KNOWLTON, Clark S. Sírios e libaneses: mobilidade social e espacial. São Paulo: Anhembi, 1961.

LIMA, Ricardo; OLIVEIRA, Rosa. Origens do mercado de trabalho urbano no Brasil: 1889 - 1930 (Datilografado). Brasília: Universidade de Brasília, [1980?].

MARTIINEZ, Elda Conzález. Los inmigrantes escogidos: los pequeños propietarios españoles en la Amazonía brasileña. Anuario Americanista Europeo, Helsinki, v. 3, n. 3, p. 1-12, 2005. Disponível em: <http://www.red-redial.net/revista/anuario-americanista-europeo/article/viewFile/100/85>. Acesso em: 3 set. 2017.

MARTINS, Ana Cecília Impellizieri; SOCHACZEWSKI, Monique. (Orgs.). As descobertas do Brasil: o olharestrangeiro na construção da imagem do Brasil. Rio de Janeiro: Casa da Palavra, 2014.

SILVA, Carmen Novoa. Um paichamado Elias. Manaus: Valer, 2010.

SMITHJÚNIOR, Francisco Pereira; GARVÃO, Rodrigo Fraga. A imigração subsidiada: os contratos para introdução de espanhóis no Pará. Crítica Histórica, Maceió, v. 6, n. 11, p. 174-195, jul. 2015. Disponível em: <http:// www.seer.ufal.br/index.php/criticahistorica/article/view/2975>. Acesso em: 22 fev. 2018.

PINHEIRO, Maria Luiza Ugarte. A cidade sobre os ombros: trabalho e conflito no porto de Manaus (1899-1925). 1996. Dissertação (Mestrado em História) - Pontifícia Universidade Católica de São Paulo, São Paulo. 1996.

SANTOS, Adair ]. História da livre iniciativa no desenvolvimento socioeconômico do Estado de Roraima. Boa Vista: Fecomércio RR, 2004.

SANTOS, Roberto. História Econômica da Amazônia (1800 - 1920). São Paulo: T. A. Queiroz, 1980.

SARGES, Maria de Nazaré. A "Galícia” paraense: imigração espanhola em Belém do Pará (1890-1910). In: ALONSO, José Luis Ruiz-Peinado; CHAMBOULEYRON, Rafael. (Orgs.). Trópicos de História: gente, espaço e tempo na Amazônia (séculos XVII a XXI). Belém: Açaí, 2010. p. 201-218. v. 1.

SOUZA, Márcio. História da Amazônia. Manaus: Valer, 2009.

TELES, Luciano Everton Costa. A Vida Operária em Manaus: imprensa e mundos do trabalho (1920). 2008. Dissertação (Mestrado em História) - Universidade Federal do Amazonas, Manaus. 2008.

. A história do trabalho no amazonas: desafios atuais. Revistá de Teoria da História, Goiânia, v. 8, n. 2, p. 20-34, mar. 2014. ISSN 2175 - 5892. Disponível em: <https://www.revistas.ufg.br/teoria/article/view/28950>. Acesso em: 22 fev. 2018.

TELES, Luciano Everton Costa. A lucta social e a existência de uma rede anarquista regional: Tércio Miranda/ AM e Antônio Carvalho/PA (1914). Revista Piauiense de História Social e do Trabalho,Parnaíba, v. 2, n. 2, p. 174195, jan./ago. 2016.

ZAIDAN, Assaad. Raízes libanesas no Pará. Belém: UFPA, 2001. 